\title{
Single versus dual operative spine fractures in ankylosing spondylitis
}

\author{
Alex Y. Lu, MD, ${ }^{1}$ Jacob S. Blitstein, MS, ${ }^{2}$ Jason F. Talbott, MD, PhD, ${ }^{3}$ Andrew K. Chan, MD, ${ }^{1}$ \\ Sanjay S. Dhall, MD, ${ }^{1}$ Ashraf N. El Naga, MD, ${ }^{4}$ Lee A. Tan, MD, ${ }^{1}$ Aaron J. Clark, MD, PhD, ${ }^{1}$ \\ Dean Chou, MD, ${ }^{1}$ Praveen V. Mummaneni, MD, MBA, ${ }^{1}$ and Anthony M. DiGiorgio, DO, MHA ${ }^{1}$
}

'Department of Neurological Surgery, University of California, San Francisco; ${ }^{2}$ Touro University California, College of Osteopathic Medicine, Vallejo; ${ }^{3}$ Department of Radiology, University of California, San Francisco; and ${ }^{4}$ Department of Orthopedic Surgery, University of California, San Francisco, California

OBJECTIVE Ankylosing spondylitis, the most common spondyloarthritis, fuses individual spinal vertebrae into long segments. The unique biomechanics of the ankylosed spine places patients at unusually high risk for unstable fractures secondary to low-impact mechanisms. These injuries are unique within the spine trauma population and necessitate thoughtful management. Therefore, the authors aimed to present a richly annotated data set of operative AS spine fractures with a significant portion of patients with simultaneous dual noncontiguous fractures.

METHODS Patients with ankylosing spondylitis with acute fractures who received operative management between 2012 and 2020 were reviewed. Demographic, admission, surgical, and outcome parameters were retrospectively collected and reviewed.

RESULTS In total, 29 patients were identified across 30 different admissions. At admission, the mean age was $71.7 \pm$ 11.8 years. The mechanism of injury in $77 \%$ of the admissions was a ground-level fall; $30 \%$ also presented with polytrauma. Of admissions, $50 \%$ were patient transfers from outside hospitals, whereas the other half presented primarily to our emergency departments. Fifty percent of patients sustained a spinal cord injury, and 35 operative fractures were identified and treated in 32 surgeries. The majority of fractures clustered around the cervicothoracic (C4-T1, 48.6\%) and thoracolumbar (T8-L3, 37.11\%) junctions. Five patients (17.2\%) had simultaneous dual noncontiguous operative fractures; these patients were more likely to have presented with a higher-energy mechanism of injury such as a bicycle or motor vehicle accident compared with patients with a single operative fracture (60\% vs $8 \%, p=0.024)$. On preoperative MRI, $56.3 \%$ of the fractures had epidural hematomas (EDHs); $25 \%$ were compressive of the underlying neural elements, which dictated the number of laminectomy levels performed (no EDH, $2.1 \pm 2.36$; noncompressive EDH, $2.1 \pm 1.85$; and compressive $\mathrm{EDH}, 7.4 \pm 4$ [ $p=0.003]$ ). The mean difference in instrumented levels was $8.7 \pm 2.6$ with a mean estimated blood loss (EBL) of $1183 \pm 1779.5 \mathrm{~mL}$. Patients on a regimen of antiplatelet therapy had a significantly higher EBL (2635.7 mL vs $759.4 \mathrm{~mL}, p=0.015$ ). Overall, patients had a mean hospital length of stay of $15.2 \pm 18.5$ days; 5 patients died during the same admission or after transfer to an outside hospital. Nine of 29 patients (31\%) had died by the last follow-up (the mean follow-up was $596.3 \pm 878.9$ days).

CONCLUSIONS Patients with AS who have been found to have unstable spine fractures warrant a thorough diagnostic evaluation to identify secondary fractures as well as compressive EDHs. These patients experienced prolonged inpatient hospitalizations with significant morbidity and mortality.

https://thejns.org/doi/abs/10.3171/2021.7.FOCUS21329

KEYWORDS ankylosing spondylitis; spine fracture; fracture dislocation; spinal cord injury

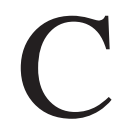
LASSIFIED as a seronegative spondyloarthropathy, ankylosing spondylitis (AS) represents the most common spondyloarthritis, affecting up to 1 in 200 individuals $^{1}$ and with a significant male predilection. As patients with AS age, they accumulate ossification of their spinal discs, joints, and ligaments, leading to a diagnosis that is often secondary to chronic back pain. ${ }^{2}$ The unique biomechanics of the ankylosed spine places patients at unusually high risk for unstable fracture secondary to low-impact mechanisms. In surgical correction, the

ABBREVIATIONS AS = ankylosing spondylitis; ASIA = American Spinal Injury Association; EBL = estimated blood loss; ED = emergency department; OSH = outside hospital.

SUBMITTED May 31, 2021. ACCEPTED July 16, 2021

INCLUDE WHEN CITING DOI: 10.3171/2021.7.FOCUS21329. 
long-segment fusion constructs secondary to poor bone quality, high intraoperative blood loss, and concomitant spinal cord injuries present multiple challenges to both patients and medical providers. Within the spine trauma population, these circumstances are distinctive and necessitate thoughtful management. Herein, we present a richly annotated data set of operative AS spine fractures with a significant portion of patients with simultaneous dual noncontiguous fractures.

\section{Methods}

\section{Patient Population}

Patients with a diagnosis of AS who were $\geq 18$ years of age at the time of the initial presentation at the University of California, San Francisco, Parnassus Heights campus and Zuckerberg San Francisco General Hospital and Trauma Center between 2012 and 2020 were reviewed. Patients who received operative management were selected and retrospectively analyzed. Patients were excluded if they had radiographic features of diffuse idiopathic skeletal hyperostosis (DISH) without AS, had osteomyelitis, had developed an infection in the setting of previous spinal surgery requiring operative management without an acute fracture, or had AS but without an acute fracture and had undergone deformity correction.

\section{Data Collection}

Demographic, admission, surgical, and outcome parameters were retrospectively collected and reviewed. Neurological status as measured by the American Spinal Injury Association (ASIA) Impairment Scale was documented both at admission and before discharge. This retrospective chart review was approved by the University of California, San Francisco, IRB.

\section{Statistical Analysis}

The data are presented as means \pm standard deviations or proportions for continuous and categorical variables. The Pearson's chi-square test $\left(\chi^{2}\right)$, Wilcoxon rank-sum exact test, Kruskal-Wallis rank-sum test, and Fisher's exact test were utilized when appropriate. Statistical significance was assessed at $p=0.05$. All statistical analyses were performed utilizing the open-source libraries of $\mathrm{R}$ version 4.1.0 (http://cran.r-project.org/). Figures were created utilizing $\mathrm{R}$ and BioRender (https://biorender.com).

\section{Results}

\section{Patient Demographics and Presentation}

In total, 29 patients were identified across 30 distinct admissions ( 1 patient was admitted twice and found to have 2 separate operative fractures). The mean age at admission was $71.7 \pm 11.8$ years, and $87 \%$ of admissions were male (Table 1). Supplemental Table 1 lists the comorbidities associated with the 11-item modified frailty index $(2.47 \pm 2.29)$ and 5-item modified frailty index (1.43 \pm 1.2 ). Of admissions, 15 (50\%) presented to our emergency departments (EDs), whereas the other 50\% were transferred from outside hospitals (OSHs). The majority of these admissions (77\%) were due to fractures from
TABLE 1. Patient demographics on admission, by number of fractures

\begin{tabular}{|c|c|c|c|c|}
\hline Characteristic & $\begin{array}{c}\text { Overall } \\
(n=30)^{*}\end{array}$ & $\begin{array}{l}\text { Single } \\
\text { Fracture } \\
(n=25)\end{array}$ & $\begin{array}{l}\text { Simultaneous } \\
\text { Dual Fracture } \\
\quad(n=5)\end{array}$ & $\begin{array}{c}p \\
\text { Value }\end{array}$ \\
\hline $\begin{array}{l}\text { Mean age at } \\
\text { presentation, } \\
\text { yrs }\end{array}$ & $71.73(11.78)$ & $72.82(10.86)$ & $66.33(15.94)$ & 0.6 \\
\hline Sex & & & & $>0.9$ \\
\hline $\mathrm{F}$ & $4(13)$ & $4(16)$ & $0(0)$ & \\
\hline$M$ & $26(87)$ & $21(84)$ & $5(100)$ & \\
\hline Mechanism & & & & 0.032 \\
\hline $\begin{array}{l}\text { Bicycle } \\
\text { accident }\end{array}$ & $1(3.3)$ & $0(0)$ & $1(20)$ & \\
\hline Fall & $23(77)$ & $21(84)$ & $2(40)$ & \\
\hline MVA & $4(13)$ & $2(8.0)$ & $2(40)$ & \\
\hline Unknown & $2(6.7)$ & $2(8.0)$ & $0(0)$ & \\
\hline Polytrauma & $9(30)$ & $6(24)$ & $3(60)$ & 0.14 \\
\hline Anticoagulation & & & & 0.5 \\
\hline None & $26(87)$ & $22(88)$ & $4(80)$ & \\
\hline $\begin{array}{l}\text { Rivaroxaban } \\
\text { (held) }\end{array}$ & $3(10)$ & $2(8.0)$ & $1(20)$ & \\
\hline $\begin{array}{l}\text { Warfarin } \\
\text { (held) }\end{array}$ & $1(3.3)$ & $1(4.0)$ & $0(0)$ & \\
\hline Antiplatelet & & & & 0.3 \\
\hline None & $24(80)$ & $21(84)$ & $3(60)$ & \\
\hline $\begin{array}{l}\text { Aspirin, } \\
81 \mathrm{mg}\end{array}$ & $5(17)$ & $3(12)$ & $2(40)$ & \\
\hline Clopidogrel & $1(3.3)$ & $1(4.0)$ & $0(0)$ & \\
\hline Presentation & & & & $>0.9$ \\
\hline ED & $15(50)$ & $12(48)$ & $3(60)$ & \\
\hline OSH transfer & $15(50)$ & $13(52)$ & $2(40)$ & \\
\hline
\end{tabular}

MVA $=$ motor vehicle accident.

Values represent the number of admissions (\%) or mean (SD).

* One patient was admitted twice.

† Wilcoxon rank-sum exact test or Fisher's exact test.

ground-level falls, with the remaining attributed to bicycle (3.3\%) or motor vehicle (13\%) accidents. Two admissions (6.7\%) were due to unknown mechanisms of injury.

Nine admissions (30\%) were found to have polytrauma. Admission neurological examinations were graded according to the ASIA scale (Supplemental Table 2); $50 \%$ of patients had a spinal cord injury on admission. At admission, 4 patients $(13.8 \%)$ were on anticoagulation therapy, whereas 6 patients $(21 \%)$ were on antiplatelet medications.

Patients presenting through the ED had a longer mean time from fracture to admission compared with patients who were transferred from an OSH (Fig. 1). This was due to a small number of patients with stable neurological examinations postfracture who were initially elected for conservative management or who had unrecognized fractures $(13.9 \pm 35.2$ vs $5.6 \pm 8$ days, $\mathrm{p}=0.024)$. However, the median time from fracture to admission was shorter for patients who presented to the ED compared with those 


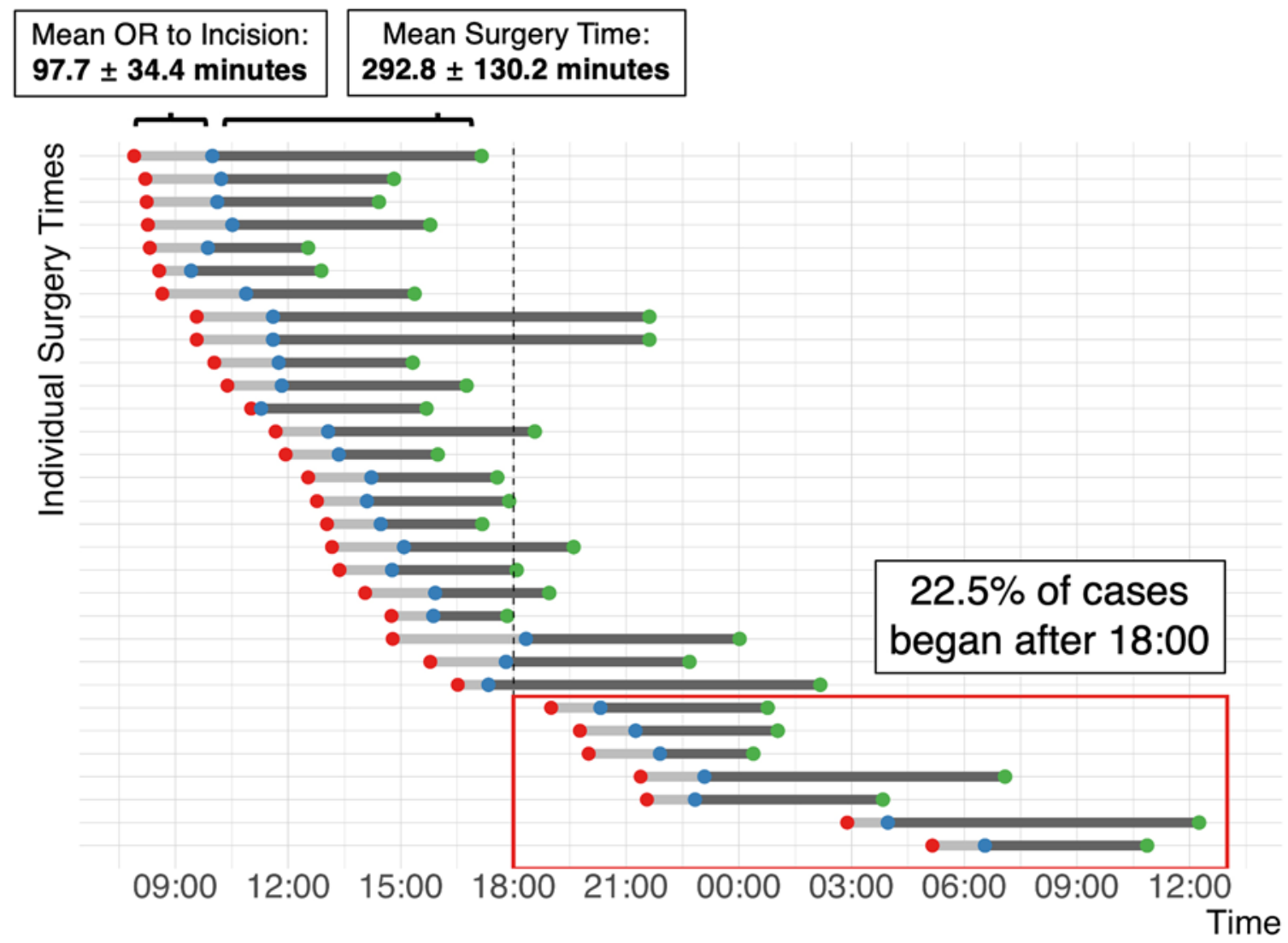

FIG. 1. Evaluation of time periods from fracture to admission, admission to surgery, and surgery to discharge.

who were transferred from an OSH (0 days vs 3 days), while the latter also had a higher proportion of spinal cord injury ( $80 \%$ vs $20 \%, \mathrm{p}=0.001$ ) and tended to have worse ASIA grades (Supplemental Table 2). There was no significant difference in medical comorbidities except for a higher proportion of congestive heart failure in patients who transferred from an OSH (Supplemental Table 1).

\section{Fracture Characteristics}

In 30 admissions, there were 35 operative fractures; postoperative imaging obtained in a representative patient is shown in Fig. 2. Excluding 1 dens fracture and 1 lumbar burst fracture, the remaining fractures (33 fractures, $94.3 \%$ ) were found to be distraction-type fractures. Of these fractures, $48.6 \%$ involved two adjacent vertebrae, primarily representing fracture dislocation injuries (Fig. 3 upper). The majority of these fractures clustered around the cervicothoracic $(\mathrm{C} 4-\mathrm{T} 1,48.6 \%)$ and thoracolumbar (T8-L3, 37.11\%) junctions. Six patients (20.7\%) had 2 operative fractures; 5 of these patients presented with dual simultaneous operative fractures in the same admission (Fig. 3 lower). Preoperative MRI found no epidural hematoma (EDH) in $43.8 \%$, noncompressive EDH in $31.3 \%$, and compressive EDHs in $25 \%$ of fractures. The presence of compressive EDHs tended to have a smaller proportion of spinal cord injury compared with those fractures with noncompressive or no EDH, but this did not reach statistical significance ( $86 \%$ vs $50 \%$ vs $31 \%, \mathrm{p}=0.087$ ).
The 5 patients with simultaneous dual fractures were more likely to present with a higher-energy mechanism of injury such as a bicycle or motor vehicle accident compared with patients with a single operative fracture $(60 \%$ vs $8 \%, p=0.024$; Table 1 ). While none of these 5 patients had compressive EDHs ( 3 of the fractures were with noncompressive EDHs), they had high ASIA grades on admission (grade $\mathrm{A}, 2$; grade $\mathrm{B}, 1$; grade $\mathrm{D}, 1$; and grade $\mathrm{E}, 1)$. The only operative midthoracic spine fractures (1 fracture at T3 and 2 fractures at T5) occurred in patients with dual simultaneous fractures (Fig. 3 lower).

\section{Surgical Management}

For the 35 operative fractures, there were 31 separate posterior operations (1 patient had 2 separate constructs in the same operation) and 32 constructs (2 patients with double fractures had 2 separate constructs). There were 3 separate anterior operations (2 anterior cervical discectomies/fusions and 1 cervical corpectomy) as well as 1 thoracic vertebral column resection performed posteriorly. As shown in Fig. 3, the mean instrumented spinal levels were $8.7 \pm 2.6$, whereas the mean levels of laminectomy were $3.5 \pm 3.5$. Thirty-three percent of the operations did not involve laminectomies. The presence of a compressive EDH led to an increase in the number of laminectomy levels performed (no EDH, $2.1 \pm 2.36$; noncompressive $\mathrm{EDH}$, $2.1 \pm 1.85$; and compressive EDH, $7.4 \pm 4$ [p < 0.003]) (Fig. 4). 

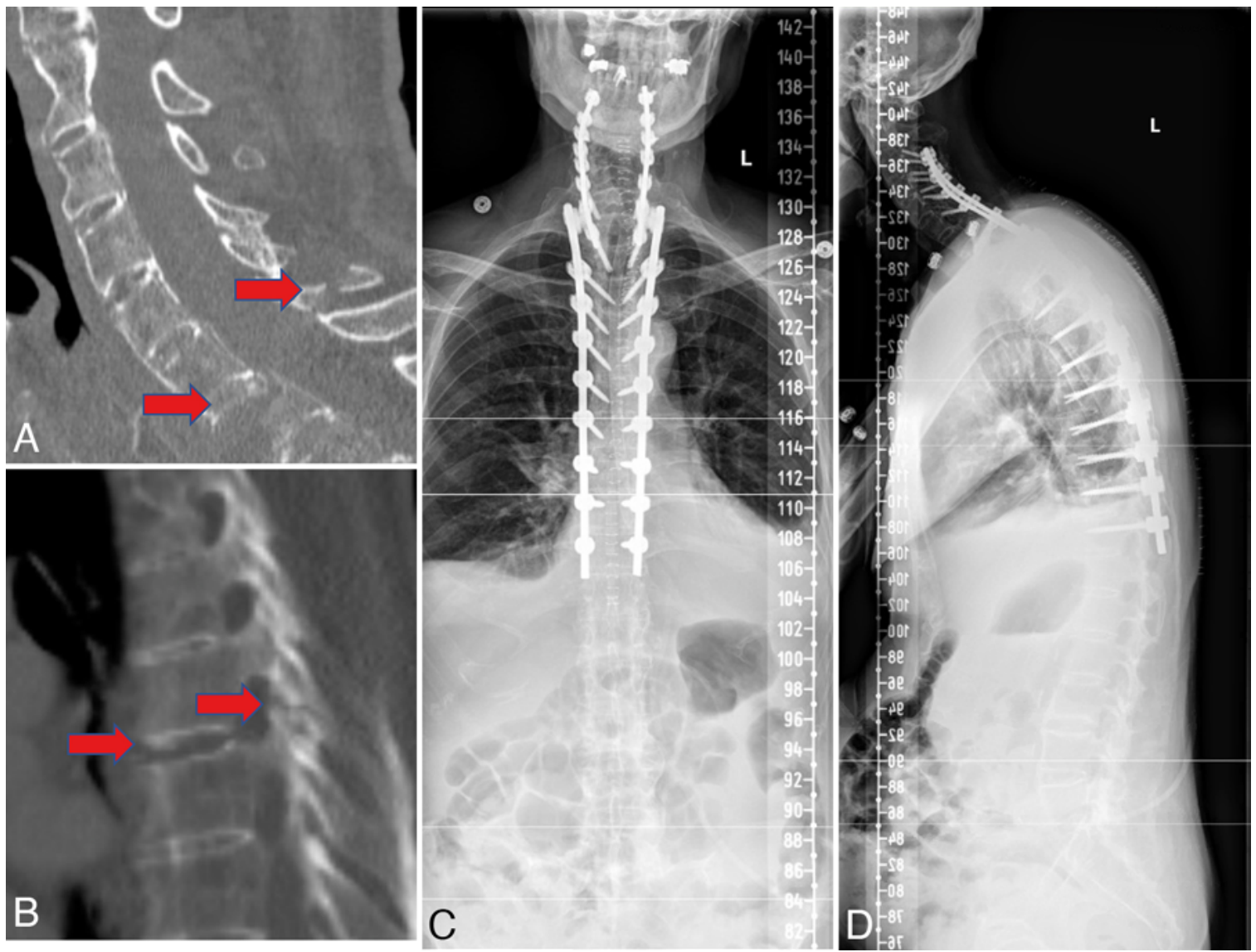

FIG. 2. Representative AS sequential fracture. A: CT scan of the cervical spine obtained in a patient who presented after a ground-level fall with a distraction injury at C6-7 (red arrows) requiring C3-T3 posterior cervical fusion. B: Three years later, the patient returned with another fall and was found to have another distraction injury, now at T8. A CT scan of the thoracic spine was obtained and showed fractures (red arrows) extending through the anteroposterior dimension of the spine. C and D: Postoperative full-length scoliosis radiographs showing the previous construct extended to T11.

For the 32 constructs, 6 operations (19\%) involved a coattending surgeon. A minimally invasive approach was used in 4 operations (12.5\%). The mean EBL was $1183 \pm$ $1779.5 \mathrm{~mL}$ per surgery. Patients on a regimen of aspirin or clopidogrel had a significantly higher mean EBL (2635.7 $\mathrm{mL}$ vs $759.4 \mathrm{~mL}, \mathrm{p}=0.015$ ). Although there was an outlier value of a 10 -mL EBL for a single patient taking clopidogrel, the median EBL was also significantly higher for patients on an 81-mg regimen of aspirin $(1250 \mathrm{~mL}$ vs 500 $\mathrm{mL}$ ). One operation (3.1\%) resulted in a CSF leak.

Once the patient was brought to the operating room, the mean time until incision was $97.7 \pm 34.4$ minutes, reflecting the amount of time needed for intubation, line placement, preflip neuromonitoring, and patient positioning. The mean surgery duration was $292.8 \pm 130.2$ minutes (Fig. 1); $22.5 \%$ of surgeries were started outside of normal working hours (after 6 PM).

\section{Patient Outcomes}

The mean time from admission to discharge was 15.2 \pm 20 days (Fig. 5). Of the 30 admissions, 19 (63\%) were associated with at least 1 complication, which included infection/sepsis, pulmonary embolism, respiratory failure, and instrumentation failure (Table 2). Four patients died during the admission, 1 patient died shortly after transfer back to the referring $\mathrm{OSH}$, and 4 patients died before the last follow-up. On discharge, patients went home (10\%), to acute rehabilitation (20\%), or to a skilled nursing facility (33\%), or they returned to an OSH (23\%). On the last follow-up, excluding the 9 patients $(31 \%)$ who had died, the final ASIA grade was improved in 8 patients (40\%), unchanged in 11 patients (55\%), and worse in 1 patient $(5 \%)$ compared with their admission ASIA grades (Fig. 6); the mean follow-up period was $596.3 \pm 878.9$ days.

Compared with patients with single fractures, the 5 patients who had dual fractures did not have a higher proportion of complications ( $60 \%$ vs $64 \%, p>0.9)$, difference in discharge disposition $(\mathrm{p}=0.7)$, or difference in admission duration $(\mathrm{p}>0.9)$.

\section{Discussion}

The pathognomonic biology of the ankylosed spine leads to unique challenges within the spine trauma population. Chronic inflammation results in diffuse osteopenia/ osteoporosis combined with long lever arms secondary to 


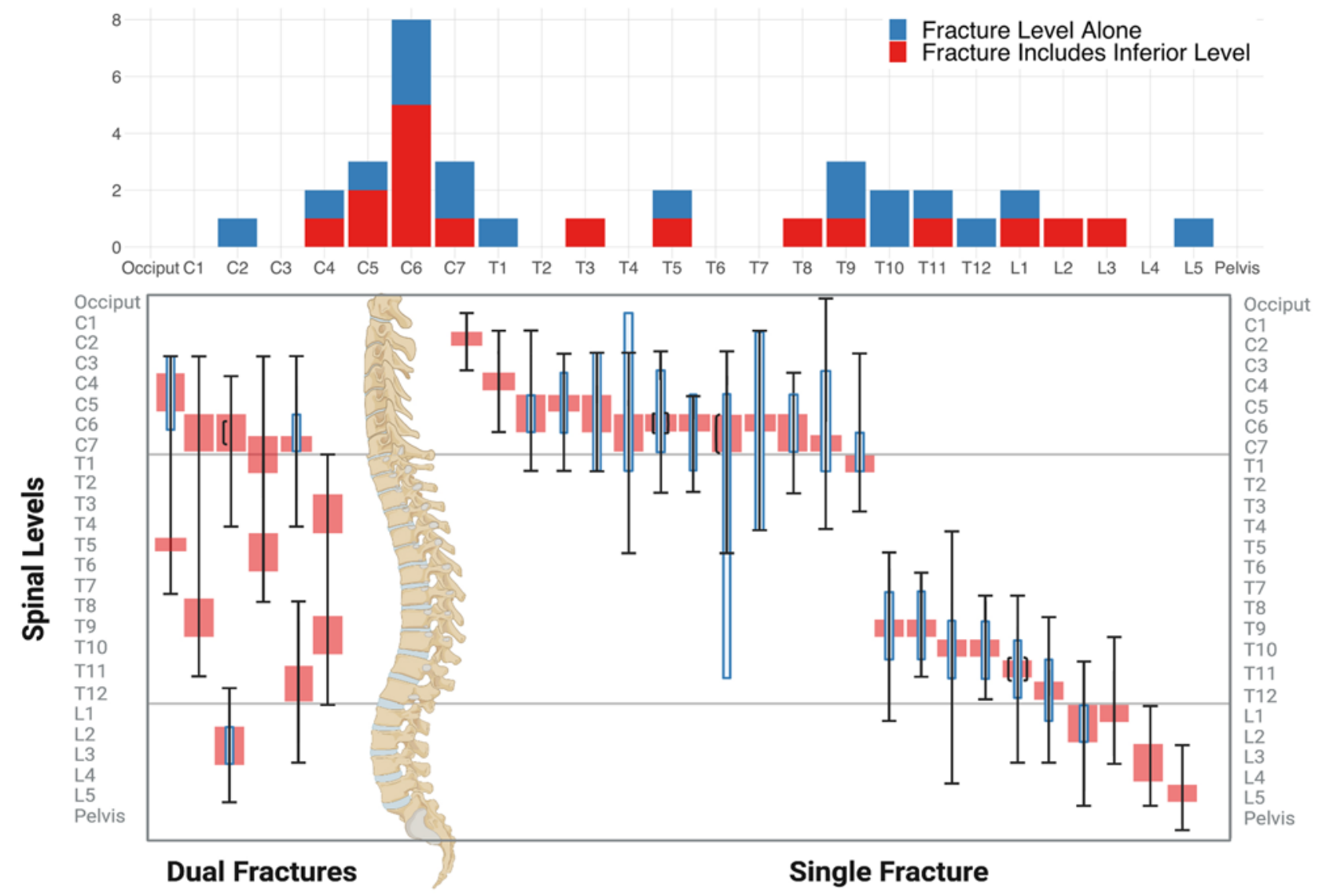

$$
\text { = Fracture } I=\text { Instrumented } \quad[\text { = Laminectomy } \quad[\text { = ACDF } \quad[]=\text { Corpectomy }
$$

FIG. 3. Upper: Bar graph showing AS fractures by spinal level. Lower: Diagram showing AS fractures by surgical construct for each patient. Made in (c) BioRender - biorender.com.

bridging syndesmophytes across multiple vertebrae. ${ }^{3} \mathrm{Mul}-$ tiple scales can measure the degree of structural change in the ankylosed spine, but this is most commonly evaluated on cervical and lumbar spine radiographs through the modified Stoke Ankylosing Spondylitis Spinal Score. ${ }^{4} \mathrm{Ra}-$ diographic progression of increased syndesmophyte burden can be seen in one-third of patients over 2 years ${ }^{3}$ and has been demonstrated to follow a linear course. ${ }^{5}$

As these changes are cumulative over time, leading to both a rigid and unbalanced spine, patients theoretically become more prone to traumatic fractures as they age. The mean age in the 7th decade of life seen in our series is slightly higher than a mean age of 63.4 years in a recent meta-analysis. ${ }^{6}$ The youngest patient in our series was 48 years old, and this is reflected in a National Inpatient Sample database analysis of patients admitted with AS fractures where less than $0.4 \%$ of fractures occurred before the age of 30 years, and $51.7 \%$ of fractures occurred after the age of 70 years?

The combined biomechanics and inflammatory changes of the ankylosed spine place patients at significant risk for developing three-column fractures from low-energy mechanisms. Similar to our results, multiple series cite falls as the most common mechanism of injury; ${ }^{6,8-10}$ falls in the AS population have also been found to increase as patients age, secondary to pain, stiffness, fatigue, and lower-extremity AS involvement. ${ }^{11}$ Other identified risk factors in the AS population include vestibular dysfunction, concurrent thoracolumbar kyphotic deformity, and proprioception deficits in the setting of osteoporosis. ${ }^{12}$ Higher-energy traumatic mechanisms led to an increase of dual fractures in our series. Simultaneous noncontiguous dual spine fractures in AS have been primarily described in case reports, ${ }^{13-16}$ with one larger case series identifying 7 patients with occult or second noncontiguous vertebral fractures. ${ }^{17}$ Another AS series identified 2 patients with 2 concurrent spinal fractures as well as 3 other patients with multiple fractures at different time points $;{ }^{18}$ however, in both case series, the specific surgical management of these patients was not described.

While it is routine to perform a global spine survey in patients with AS who experience trauma, our findings suggest that additional scrutiny should be employed when patients with AS present with higher-impact mechanisms of injury. This may also suggest that the location of fractures in the ankylosed spine requires differential traumatic forc- 
A
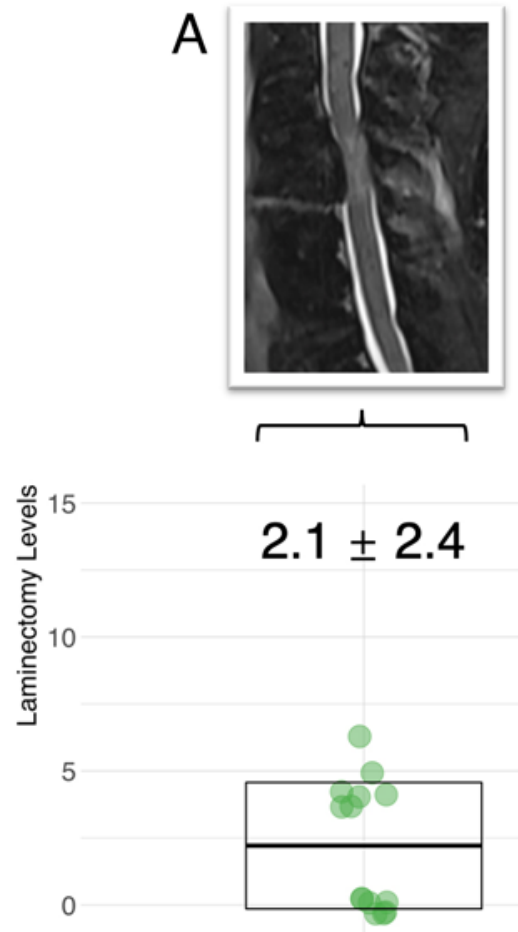

No Epidural Hematoma
B

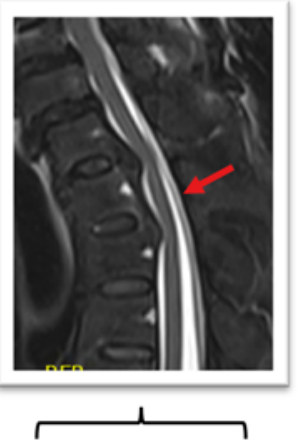

$2.1 \pm 1.9$

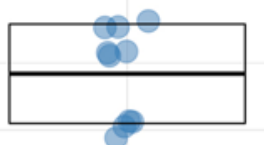

Non-compressive Epidural Hematoma Compressive Epidural Hematoma

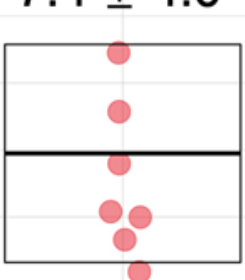

FIG. 4. Comparison of EDH presence and the number of laminectomy levels. Representative MR images of no EDH (A), noncompressive EDH (arrow, B), and compressive EDH (arrow, C) are shown.

\begin{tabular}{|l|c|}
\hline Time Period & $\begin{array}{c}\text { Mean Days } \\
(\mathbf{n}=\mathbf{3 0})\end{array}$ \\
\hline $\begin{array}{l}\text { Fracture to } \\
\text { Admission }\end{array}$ & $9.73 \pm 25.45$ \\
\hline $\begin{array}{l}\text { Admission to } \\
\text { Surgery }\end{array}$ & $2.03 \pm 3.02$ \\
\hline $\begin{array}{l}\text { Surgery to } \\
\text { Discharge }\end{array}$ & $13.17 \pm 18.88$ \\
\hline $\begin{array}{l}\text { Admission to } \\
\text { Discharge }\end{array}$ & $15.20 \pm 20$ \\
\hline
\end{tabular}

Fracture to Admission $\square$ Admission to Surgery $\square$ Surgery to Discharge

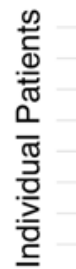

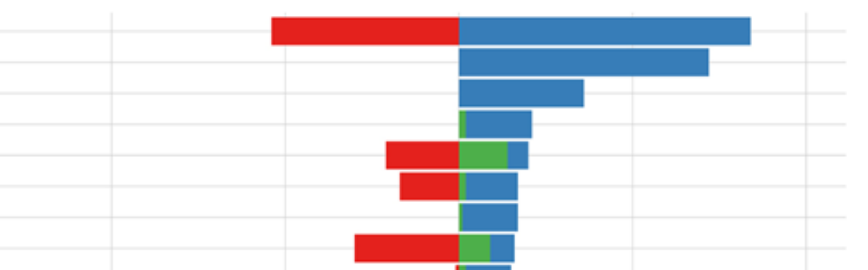

(1)

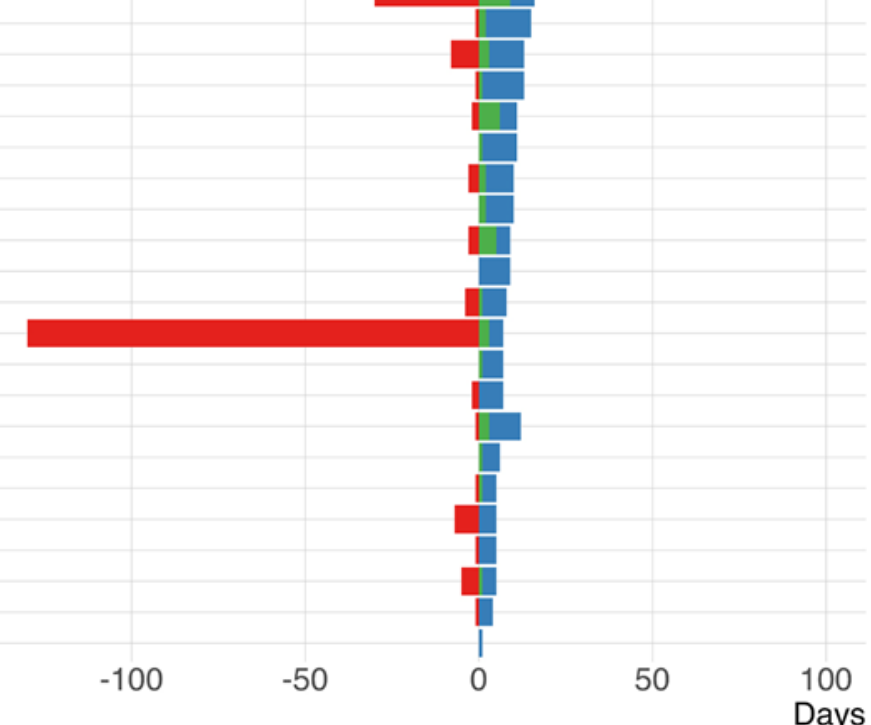

FIG. 5. Graph showing surgery duration from operating room arrival (red dot), to the start of surgery (blue dot), to the end of surgery (green dot). 
TABLE 2. Patient complications

\begin{tabular}{lccc}
\hline \multicolumn{1}{c}{$\begin{array}{c}\text { Medical } \\
\text { Complication }\end{array}$} & $\begin{array}{c}\text { No. of } \\
\text { Admissions } \\
(\%)\end{array}$ & $\begin{array}{c}\text { Surgical } \\
\text { Complication }\end{array}$ & $\begin{array}{c}\text { No. of } \\
\text { Admissions } \\
(\%)\end{array}$ \\
\hline Pneumonia & $7(23.3)$ & Hardware failure & $2(6.7)$ \\
\hline Sepsis & $3(10)$ & Wound infection & $1(3.3)$ \\
\hline $\begin{array}{l}\text { Clostridium difficile } \\
\text { infection }\end{array}$ & $2(6.7)$ & Osteomyelitis & $1(3.3)$ \\
\hline Respiratory failure & $1(3.3)$ & & \\
\hline UTI & $1(3.3)$ & & \\
\hline GI bleed & $1(3.3)$ & & \\
\hline PEA arrest & $1(3.3)$ & & \\
\hline Dysphagia & $1(3.3)$ & & \\
\hline Renal failure & $1(3.3)$ & & \\
\hline CHF exacerbation & $1(3.3)$ & & \\
\hline Dysphagia & $1(3.3)$ & & \\
\hline Total & $20(66.7)$ & & \\
\hline
\end{tabular}

$\mathrm{CHF}=$ congestive heart failure; $\mathrm{GI}=$ gastrointestinal; $\mathrm{PEA}=$ pulseless electrical activity; UTI = urinary tract infection.

es. While patients with single fractures typically present with fractures at the cervicothoracic and thoracolumbar junction due to the long lever arms in these areas and due to the transition of lordosis and kyphosis, the only midthoracic fractures in this series occurred from high-force mechanisms and all were in the setting of simultaneous dual fractures. This is reflected in the general spinal cord injury population where injury level at the midthoracic spine is rare without an underlying mass lesion. ${ }^{19}$

When evaluating patients with AS, the unstable nature and high proportion of neurological deficits make expedient treatment a necessity. Fractures in AS without instability can occasionally be managed with brace or halo orthosis alone,$^{20}$ although this approach is not appropriate for patients with unstable fractures with neurological deficit/compressive EDH or for patients who would not tolerate extended external bracing. Almost one-quarter of our patients had surgical intervention that began outside of standard work hours (after 6 PM), which reflects our center's goal of early surgical intervention in patients with spinal cord injury and/or neurological deficit. ${ }^{21}$ Due to the expected high blood loss requiring large-bore intravenous access, difficulty positioning secondary to often concurrent spinal instability/deformity, and utilization of preflip neuromonitoring, our expected time from arrival to the operating room to skin incision was more than 90 minutes. This use of time and operating room resources must be weighed while planning the optimum surgical treatment plan.

Our surgical treatment plan reflects the known maxim of fusing patients with AS " 3 up and 3 down" due to the unstable distraction-type fractures and poor bone quality secondary to concomitant osteopenia/osteoporosis. Most of our procedures were done from a posterior-only approach, none with a purely anterior approach. A com-
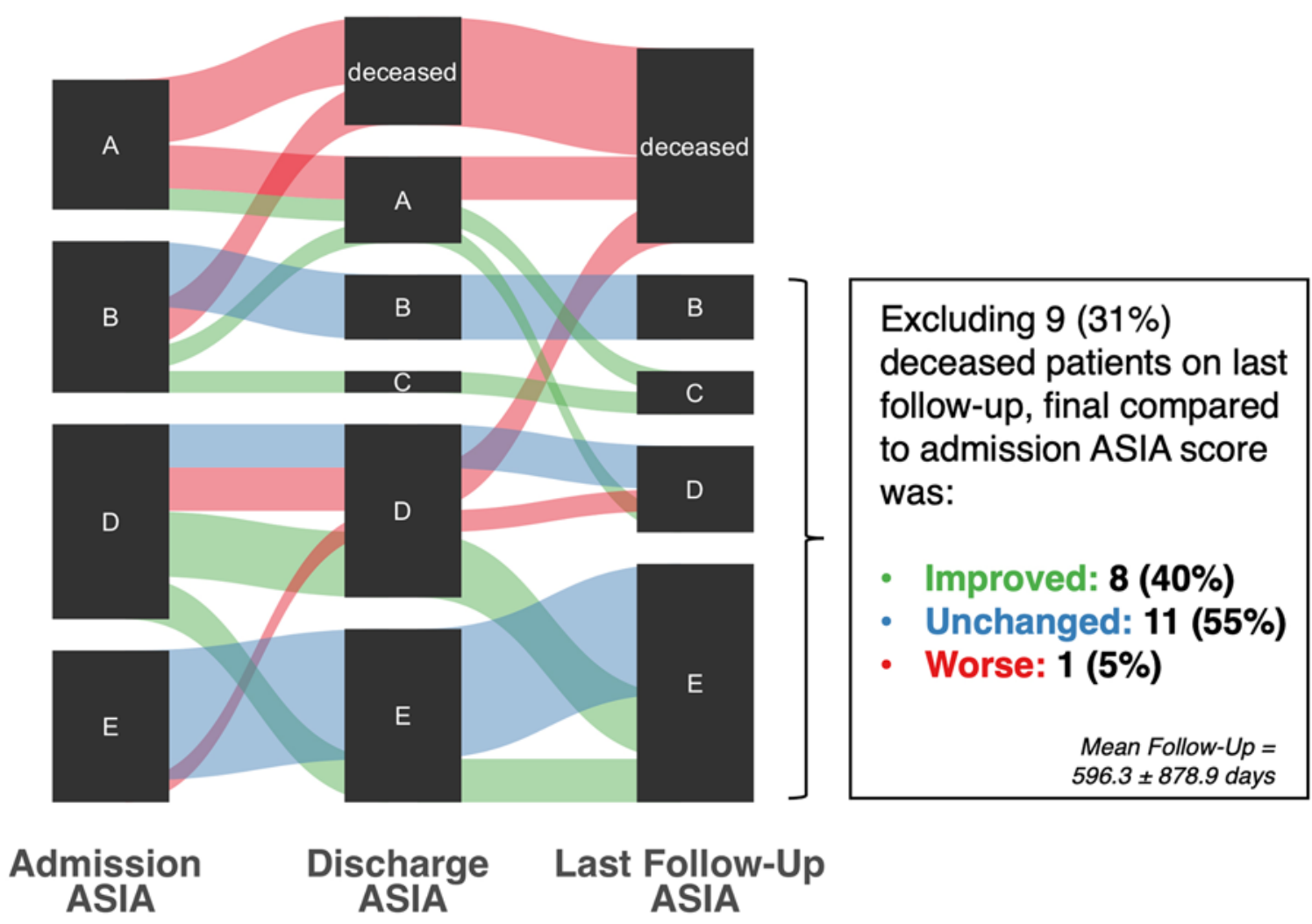

FIG. 6. Comparison of ASIA grades at admission, discharge, and the last follow-up. 
bined anterior-posterior approach was most commonly used in the cervical spine similar to that of other operative series, ${ }^{18,22-24}$ each patient's fracture should be individually assessed for the need for circumferential stabilization. ${ }^{25,26}$

In this series, the degree of EDH determined the number of laminectomy levels with the goal of complete decompression of underlying neural elements. While not achieving statistical significance, the presence of compressive EDH trended with spinal cord injury concurrence. Other case reports and series have associated neurological deficit with the presence of spinal epidural and/or subdural hematoma. $27-30$

In AS, the chronic inflammatory changes of the soft tissues adjacent to an unstable fracture and bleeding-prone bone also lead to a higher operative blood loss. Although many anticoagulation medications can be safely reversed or held within 48 hours of surgical intervention, antiplatelet medications have not been proven to be completely efficacious reversing agents. Restoration of platelet action after stopping antiplatelet medications requires between 5 and 7 days. $^{31}$ Alongside nonsteroidal antiinflammatory drugs, aspirin is commonly used in patients with AS for pain management and for primary prevention of atherosclerotic cardiovascular disease. Our results suggest that patients with AS who were on aspirin at the time of the surgical correction had significantly higher surgical blood loss. Patients with AS who are prone to falling should have the risks of prophylactic aspirin treatment weighed.

Our series also demonstrated a high rate of medical comorbidities at the time of admission as well as significant morbidity and mortality at discharge and the last followup, similar to other published series. ${ }^{18,20,23,24,32}$ However, long-term neurological prognosis can be guarded, as $40 \%$ of patients in our series had an improved ASIA grade from admission to discharge/follow-up.

\section{Limitations}

This study is limited by the retrospective analysis of this series. Because of the rarity of operative AS fractures, our series is underpowered for certain comparisons between patients with single and dual fractures. Long-term follow-up in this series was limited due to patients being transferred back to the referring OSH and, consequently, lost to follow-up.

\section{Conclusions}

Spine fractures in AS can occur secondary to lowimpact mechanisms of injury. Patients with high-impact trauma should be scrutinized for multiple unstable fractures and compressive EDHs, as both dictate operative planning. Patients with AS ultimately experienced prolonged inpatient hospitalization with significant morbidity and mortality.

\section{References}

1. Golder V, Schachna L. Ankylosing spondylitis: an update. Rheumatology. 2013;42(11):780-784.

2. Hitchon PW, From AM, Brenton MD, Glaser JA, Torner JC. Fractures of the thoracolumbar spine complicating ankylosing spondylitis. J Neurosurg. 2002;97(2)(suppl):218-222.
3. Tan S, Wang R, Ward MM. Syndesmophyte growth in ankylosing spondylitis. Curr Opin Rheumatol. 2015;27(4):326-332.

4. Creemers MC, Franssen MJ, van't Hof MA, Gribnau FW, van de Putte LB, van Riel PL. Assessment of outcome in ankylosing spondylitis: an extended radiographic scoring system. Ann Rheum Dis. 2005;64(1):127-129.

5. Ramiro S, Stolwijk C, van Tubergen A, van der Heijde D, Dougados M, van den Bosch F, Landewé R. Evolution of radiographic damage in ankylosing spondylitis: a 12 year prospective follow-up of the OASIS study. Ann Rheum Dis. 2015;74(1):52-59.

6. Rustagi T, Drazin D, Oner C, York J, Schroeder GD, Vaccaro AR, et al. Fractures in spinal ankylosing disorders: a narrative review of disease and injury types, treatment techniques, and outcomes. J Orthop Trauma. 2017;31(suppl 4):S57-S74.

7. Lukasiewicz AM, Bohl DD, Varthi AG, Basques BA, Webb ML, Samuel AM, Grauer JN. Spinal fracture in patients with ankylosing spondylitis: cohort definition, distribution of injuries, and hospital outcomes. Spine (Phila Pa 1976). 2016; 41(3):191-196.

8. Vosse D, Landewé R, van der Heijde D, van der Linden S, van Staa TP, Geusens P. Ankylosing spondylitis and the risk of fracture: results from a large primary care-based nested case-control study. Ann Rheum Dis. 2009;68(12):1839-1842.

9. Feldtkeller E, Vosse D, Geusens P, van der Linden S. Prevalence and annual incidence of vertebral fractures in patients with ankylosing spondylitis. Rheumatol Int. 2006;26(3):234239.

10. Nugent M, Berney MJ, Morris S. Clinical outcomes following spinal fracture in patients with ankylosing spondylitis. Ir J Med Sci. 2017;186(3):677-681.

11. Dursun N, Sarkaya S, Ozdolap S, Dursun E, Zateri C, Altan L, et al. Risk of falls in patients with ankylosing spondylitis. J Clin Rheumatol. 2015;21(2):76-80.

12. Fatemi G, Gensler LS, Learch TJ, Weisman MH. Spine fractures in ankylosing spondylitis: a case report and review of imaging as well as predisposing factors to falls and fractures. Semin Arthritis Rheum. 2014;44(1):20-24.

13. Samartzis D, Anderson DG, Shen FH. Multiple and simultaneous spine fractures in ankylosing spondylitis: case report. Spine (Phila Pa 1976). 2005;30(23):E711-E715.

14. Akman MN, Karatas M, Kilinç S, Ağildere M. Double spinal cord injury in a patient with ankylosing spondylitis. Spinal Cord. 1999;37(4):305-307.

15. Ushijima T, Kawaguchi K, Matsumoto T, Takagi M, Kondoh $\mathrm{T}$, Nishimura G, et al. Double non-contiguous fractures in a patient with spondylo-epiphyseal dysplasia with spinal ankylosis treated with open and percutaneous spinal fixation technique: a case report. BMC Res Notes. 2018;11(1):106.

16. Harrop JS, Sharan A, Anderson G, Hillibrand AS, Albert TJ, Flanders A, Vaccaro AR. Failure of standard imaging to detect a cervical fracture in a patient with ankylosing spondylitis. Spine (Phila Pa 1976). 2005;30(14):E417-E419.

17. Finkelstein JA, Chapman JR, Mirza S. Occult vertebral fractures in ankylosing spondylitis. Spinal Cord. 1999;37(6): 444-447.

18. Fox MW, Onofrio BM, Kilgore JE. Neurological complications of ankylosing spondylitis. J Neurosurg. 1993;78(6): 871-878

19. Sekhon LHS, Fehlings MG. Epidemiology, demographics, and pathophysiology of acute spinal cord injury. Spine (Phila Pa 1976). 2001;26(24)(suppl):S2-S12.

20. Weinstein PR, Karpman RR, Gall EP, Pitt M. Spinal cord injury, spinal fracture, and spinal stenosis in ankylosing spondylitis. J Neurosurg. 1982;57(5):609-616.

21. Burke JF, Yue JK, Ngwenya LB, Winkler EA, Talbott JF, Pan JZ, et al. Ultra-early ( $<12$ hours) surgery correlates with higher rate of American Spinal Injury Association Impair- 
ment Scale conversion after cervical spinal cord injury. Neurosurgery. 2019;85(2):199-203.

22. He A, Xie D, Cai X, Qu B, Kong Q, Xu C, et al. One-stage surgical treatment of cervical spine fracture-dislocation in patients with ankylosing spondylitis via the combined anterior-posterior approach. Medicine (Baltimore). 2017; 96(27):e7432.

23. Ma J, Wang C, Zhou X, Zhou S, Jia L. Surgical therapy of cervical spine fracture in patients with ankylosing spondylitis. Medicine (Baltimore). 2015;94(44):e1663.

24. Olerud C, Frost A, Bring J. Spinal fractures in patients with ankylosing spondylitis. Eur Spine J. 1996;5(1):51-55.

25. Longo UG, Loppini M, Petrillo S, Berton A, Maffulli N, Denaro V. Management of cervical fractures in ankylosing spondylitis: anterior, posterior or combined approach? $\mathrm{Br}$ Med Bull. 2015;115(1):57-66.

26. Kanter AS, Wang MY, Mummaneni PV. A treatment algorithm for the management of cervical spine fractures and deformity in patients with ankylosing spondylitis. Neurosurg Focus. 2008;24(1):E11.

27. Elgafy H, Bransford RJ, Chapman JR. Epidural hematoma associated with occult fracture in ankylosing spondylitis patient: a case report and review of the literature. $J$ Spinal Disord Tech. 2011;24(7):469-473.

28. Esfahani DR, Shah HP, Behbahani M, Arnone GD, Mehta AI. Spinal subdural hematoma and ankylosing spondylitis: case report and review of literature. Spinal Cord Ser Cases. 2018;4:30.

29. Vierunen RM, Koivikko MP, Siironen JO, Kerttula LI, Bensch FV. Post-traumatic spinal hematoma in ankylosing spondylitis. Emerg Radiol. 2021;28(3):601-611.

30. Ricart PA, Verma R, Fineberg SJ, Fink KY, Lucas PA, Lo Y, et al. Post-traumatic cervical spine epidural hematoma: Incidence and risk factors. Injury. 2017;48(11):2529-2533.

31. Bultas J. Antiplatelet therapy-A pharmacologist's perspective. Cor Vasa. 2013;55(2):e86-e94.

32. Wysham KD, Murray SG, Hills N, Yelin E, Gensler LS. Cervical spinal fracture and other diagnoses associated with mortality in hospitalized ankylosing spondylitis patients. Arthritis Care Res (Hoboken). 2017;69(2):271-277.

\section{Disclosures}

Dr. Talbott reports research support from Department of Defense Grant SC120259, and is a consultant for StemCells, Inc. Dr. Chan reports research support for a nonrelated study from Orthofix
Inc. Dr. Dhall is a consultant for and has received honoraria from DePuy Spine and Globus Medical and is a patent holder with Great Circle Technologies. Dr. Tan is a consultant for Medtronic, Stryker/K2M, and Integrity Implants. Dr. Clark reports being a consultant for Globus and receiving non-study-related clinical or research effort from NuVasive. Dr. Chou is a consultant for Globus and Orthofix and receives royalties from Globus. Dr. Mummaneni reports being a consultant for DePuy Synthes, Globus, and Stryker; having direct stock ownership in Spinicity/ ISD; receiving non-study-related clinical and research grant support from NREF, AO Spine, NIH, and ISSG; and receiving royalties from DePuy Spine, Thieme Publishers, and Springer Publishers.

\section{Author Contributions}

Conception and design: all authors. Acquisition of data: DiGiorgio, Lu, Blitstein, Chan. Analysis and interpretation of data: DiGiorgio, Lu, Blitstein, Mummaneni. Drafting the article: DiGiorgio, Lu, Blitstein, Mummaneni. Critically revising the article: DiGiorgio, Lu, Blitstein, Tan, Clark, Chou, Mummaneni. Reviewed submitted version of manuscript: DiGiorgio, Lu, Blitstein, Talbott, Chan, Dhall, El Naga. Approved the final version of the manuscript on behalf of all authors: DiGiorgio. Statistical analysis: Lu. Administrative/technical/material support: DiGiorgio, Lu, Blitstein. Study supervision: all authors.

\section{Supplemental Information Videos}

Video Abstract. https://vimeo.com/596505810.

\section{Online-Only Content}

Supplemental material is available online. Supplemental Tables 1 and 2. https://thejns.org/doi/suppl/ 10.3171/2021.7.FOCUS21329.

\section{Correspondence}

Anthony M. DiGiorgio: University of California, San Francisco, CA. anthony.digiorgio@ucsf.edu. 